\title{
Indoor and Ambient Air Pollution in Chennai, India during COVID-19 Lockdown: An Affordable Sensors Study
}

\section{Naveen Puttaswamy ${ }^{1 *}$, V. Sreekanth ${ }^{2}$, Ajay Pillarisetti ${ }^{3}$, Adithi R. Upadhya ${ }^{4}$, Sudhakar Saidam ${ }^{1}$, Balachandar Veerappan ${ }^{1}$, Krishnendu Mukhopadhyay ${ }^{1}$, Sankar Sambandam ${ }^{1}$, Ronak Sutaria ${ }^{5}$, Kalpana Balakrishnan ${ }^{1}$}

\author{
${ }^{1}$ Department of Environmental Health Engineering, Faculty of Public Health, Sri Ramachandra \\ Institute of Higher Education and Research, Chennai 600 116, India \\ ${ }^{2}$ Center for Study of Science, Technology and Policy, Bengaluru 560 094, India \\ ${ }^{3}$ Gangarosa Department of Environmental Health, Rollins School of Public Health, Emory \\ University, Atlanta, USA \\ ${ }^{4}$ ILK Labs, Bengaluru, India \\ ${ }^{5}$ Respirer Living Sciences Private Limited, Pune, India
}

\section{ABSTRACT}

The Tamil Nadu Air Pollution and Health Effects study (TAPHE-2) aims to evaluate the relationship between air pollution and birth outcome in a rural-urban cohort of 300 pregnant women. Due to COVID-19 related lockdowns, some TAPHE-2 activities were delayed; however, continuous indoor and outdoor air quality data were collected in and around Chennai, India. We report here the impact of graded COVID-19 lockdown on indoor particulate matter (PM2.5 and $\mathrm{PM}_{10}$ ) levels based on calibrated data from affordable real-time PM sensors called atmos ${ }^{\mathrm{TM}}$ and ambient PM levels from publicly available regulatory monitors. The study period was between 11 March and 30 June 2020 (i.e., 100 days of continuous monitoring), which coincided with four phases of a nationwide graded lockdown. Field calibration coefficients for the atmos PM were derived by collocating them with reference-grade PM monitors. The normalized root mean square error (NRMSE) of the atmos hourly $\mathrm{PM}_{2.5}\left(\mathrm{PM}_{10}\right)$ improved from $41 \%$ to $15 \%$ (33\% to $18 \%$ ) after applying the field calibration coefficients. Lockdowns resulted in significant reductions in indoor and ambient PM levels, with the highest reduction observed during lockdown phase 2 (L2) and phase 3 (L3). Reductions as high as 70\%, 91\%, and 62\% were observed in ambient $\mathrm{PM}_{2.5}$, indoor $\mathrm{PM}_{2.5}$, and indoor $\mathrm{PM}_{10}$ relative to pre-lockdown levels (PL), respectively. The indoor $\mathrm{PM}_{2.5} / \mathrm{PM}_{10}$ ratio decreased during the lockdown, suggesting a decline in the fine mode dominance in $\mathrm{PM}_{10}$. The indoor-to-outdoor ( $\mathrm{I} / \mathrm{O})$ ratios in $\mathrm{PM}_{2.5}$ marginally increased during $\mathrm{L} 1, \mathrm{~L} 2$, and $\mathrm{L} 3$ phases compared to that of PL levels, suggesting an uneven reduction in indoor and ambient $\mathrm{PM}_{2.5}$ levels during the lockdown.

${ }^{*}$ Corresponding Author: Naveen@ehe.org.in

Publisher:

Taiwan Association for Aerosol Research

ISSN: $1680-8584$ print

ISSN: 2071-1409 online

Copyright: The Author's institution. This is an open access article distributed under the terms of the Creative Commons

Attribution License (CC BY 4.0), which permits unrestricted use, distribution, and reproduction in any medium, provided the original author and source are cited.
Keywords: Optical scattering, $\mathrm{PM}_{2.5}, \mathrm{PM}_{10}$, Beta Attenuation Monitor, Indoor to outdoor ratio

\section{INTRODUCTION}

Air pollution continues to be a significant environmental and public health issue in Indian megacities. The disease burden attributable to air pollution is predominantly driven by $\mathrm{PM}_{2.5}$ (mass concentration of particulate matter with an aerodynamic diameter of $2.5 \mu \mathrm{m}$ and less). An estimated 0.67 million (95\% uncertainty interval: $0.55-0.79$ ) and 0.48 million (95\% uncertainty interval: 0.39-0.58) premature deaths in India (in 2017) were attributed to ambient and household particulate matter pollution, respectively (Balakrishnan et al., 2019). The annual average population-weighted $\mathrm{PM}_{2.5}$ exposures in India have been increasing steadily from $62 \mu \mathrm{g} \mathrm{m}^{-3}$ in 
in 2010 to $83.2 \mu \mathrm{g} \mathrm{m}^{-3}$ in 2019 (HEI, 2020). These exposure levels are among the highest in the world-higher than China (1.7×), Nigeria $(1.2 \times)$, Bangladesh $(1.3 \times)$, Pakistan $(1.3 \times)$, Brazil $(7 \times)$, the United Kingdom $(8 \times)$, and the United States $(11 \times)(\mathrm{HEI}, 2020)$. The current state of air pollution in India poses a serious challenge to public health.

Ground-based monitoring of particulate pollution in India is sparse compared to other countries. In September 2019, India's Pollution Control Board (CPCB) had 793 operating stations, 200 of which are continuous air pollution monitoring stations (https://cpcb.nic.in/monitoringnetwork-3/). This translates to a density of 0.15 to 0.24 monitors per million people in contrast to 3.5 monitors per million in the United States and 1.2 monitors per million in China (Brauer et al., 2019). Rural areas, home to approximately 892 million (i.e., $66 \%$ of India's population), remain largely unmonitored. Besides, indoor air pollution levels are largely unknown, without any regular/organized monitoring. Only a limited amount of data on indoor air quality is available through published research studies. As people spend most of their time (in a day) indoors, household air pollution levels better represent true personal exposure, and are helpful in deriving health-relevant risk estimates. In addition to outdoor sources, specific indoor sources such as fuel combustion, incense burning, smoking, mosquito repellents, emissions from building materials, furnishing, paints, and so on, typical of Indian household settings, can contribute substantially to indoor PM levels, driving personal exposure higher than ambient air pollution (Sanchez et al., 2020).

Unobtrusive monitoring is preferred when measuring indoor air pollution. Recent advancements in sensors and wireless communication technologies have enabled the development of portable, inexpensive, internet of things (IOT)-based PM monitors that are well suited for indoor measurements. Once installed, these sensors collect continuous real-time data and transmit it to cloud servers using either General Packet Radio Service (GPRS) or Wi-Fi services. Across the world, including in India, several studies have demonstrated the accuracy, reliability, and applicability of these portable PM sensors for a variety of monitoring configurations (e.g., Malings et al., 2020; Magi et al., 2020; Sahu et al., 2020).

To contain the novel coronavirus (COVID-19), India announced a nationwide lockdown in March 2020, forcing a sudden shutdown of transportation, industry, educational institutions, and all kinds of commerce. Severe restrictions on movement were imposed, forcing people to shelter at home. The nationwide lockdown continued under several phases, with different levels of restrictions and relaxations. This situation provided a unique opportunity to study the impact of highly restricted outdoor activities on indoor and ambient air pollution levels in the megacity of Chennai. While many recent studies have reported a significant improvement in ambient air quality across India during the COVID-19 lockdown period (Mahato and Ghosh, 2020; Mahato et al., 2020; Sreekanth et al., 2021; Mor et al., 2021; Panda et al., 2021; Singh and Tyagi, 2021), not much is known about the status of indoor air quality during the lockdown phases of the COVID-19 First Wave. As people were forced to stay home, a significant increase in indoor activities - and potentially, emissions - could be expected. This can result in a competing situation between the: (i) reduction in indoor air pollution due to reduction in infiltration (of ambient air pollution), and (ii) increase in indoor air pollution due to increase in polluting household activities (e.g., cooking). The present study report results from first-of-its-kind measurements of real-time indoor PM in urban homes of Chennai city along with ambient $\mathrm{PM}_{2.5}$ during various phases of COVID-19 lockdowns. These households are part of the ongoing Tamil Nadu Air Pollution and Health Effects (TAPHE-2) mother-child cohort study.

\section{METHODS}

\subsection{Study Period and Site Characteristics}

Indoor PM monitoring in the living rooms of the TAPHE-2 cohort homes $(n=05)$ was performed using portable real-time atmos sensors between March and June 2020. The monitoring periods coincided with the pre-lockdown, lockdown, and unlock phases of the COVID-19 First Wave in 2020 (Table 1). Among the five homes monitored, Maathur (MTR) was located in an industrial area and Vanagaram (VAN) was located in a commercial area, while all other homes were from residential locations (Table 2). Built environment characteristics and possible sources contributing to indoor PM levels in these homes are summarized in Table 2. Ambient $\mathrm{PM}_{2.5}$ data across 
Table 1. Periods of different COVID-19 lockdown phases in Chennai and across India.

\begin{tabular}{|c|c|c|c|}
\hline Lockdown phase & $\begin{array}{l}\text { From date } \\
\text { (dd/mm/yyyy) }\end{array}$ & $\begin{array}{l}\text { To date } \\
\text { (dd/mm/yyyy) }\end{array}$ & Outdoor activities/services allowed \\
\hline Pre-lockdown (PL) & 01/01/2020 & $25 / 03 / 2020$ & Business-as-usual \\
\hline Lockdown Phase I (L1) & $25 / 03 / 2020$ & $14 / 04 / 2020$ & $\begin{array}{l}\text { Only emergency and essential services } \\
\text { Public and industrial activities shutdown }\end{array}$ \\
\hline Lockdown Phase II (L2) & $15 / 04 / 2020$ & 03/05/2020 & $\begin{array}{l}\text { Only emergency and essential services } \\
\text { Public and industrial activities shutdown }\end{array}$ \\
\hline Lockdown Phase III (L3) & $04 / 05 / 2020$ & $17 / 05 / 2020$ & $\begin{array}{l}\text { Construction activities during the day } \\
\text { Industry operation allowed with 50\% staff }\end{array}$ \\
\hline Lockdown Phase IV (L4) & $18 / 05 / 2020$ & $31 / 05 / 2020$ & $\begin{array}{l}\text { Public transport by road, air, and trains } \\
\text { Commercial vehicles and cargo transport }\end{array}$ \\
\hline Unlock I (UL1) & $01 / 06 / 2020$ & $30 / 06 / 2020$ & $\begin{array}{l}\text { Reopened public places, malls, places of worship, } \\
\text { restaurants, recreation, and tourism }\end{array}$ \\
\hline
\end{tabular}

Table 2. Household characteristics and probable factors contributing to indoor PM levels.

\begin{tabular}{|c|c|c|c|c|c|}
\hline Household characteristic & $\begin{array}{l}\text { Arumbakkam } \\
\text { (APM) }\end{array}$ & $\begin{array}{l}\text { Avadi } \\
\text { (AVD) }\end{array}$ & $\begin{array}{l}\text { Vanagaram-GT } \\
\text { (VGT) }\end{array}$ & $\begin{array}{l}\text { Maathur } \\
\text { (MTR) }\end{array}$ & $\begin{array}{l}\text { Vanagaram } \\
\text { (VAN) }\end{array}$ \\
\hline GPS coordinates & $\begin{array}{l}13.069^{\circ} \mathrm{N} \\
80.209^{\circ} \mathrm{E}\end{array}$ & $\begin{array}{l}13.100^{\circ} \mathrm{N} \\
80.106^{\circ} \mathrm{E}\end{array}$ & $\begin{array}{l}13.067^{\circ} \mathrm{N} \\
80.152^{\circ} \mathrm{E}\end{array}$ & $\begin{array}{l}13.175^{\circ} \mathrm{N} \\
80.249^{\circ} \mathrm{E}\end{array}$ & $\begin{array}{l}13.062^{\circ} \mathrm{N} \\
80.147^{\circ} \mathrm{E}\end{array}$ \\
\hline Location & Residential & Residential & Residential & Industrial & Commercial \\
\hline House age (years) & 4 & 26 & 10 & 5 & 6 \\
\hline House type & Shared & Independent & Shared & Shared & Shared \\
\hline Family size & 3 & 3 & 3 & 5 & 6 \\
\hline Living room size $\left(\mathrm{m}^{2}\right)$ & 12 & 13 & 25 & 10 & 8 \\
\hline Primary cooking fuel & LPG & LPG & LPG & LPG & LPG \\
\hline Distance to highway (m) & 200 & 700 & 500 & 100 & 50 \\
\hline $\begin{array}{l}\text { Distance to nearest traffic } \\
\text { junction }(\mathrm{m})\end{array}$ & 100 & 500 & 500 & 100 & 50 \\
\hline Active smoker in house & No & No & No & No & Yes \\
\hline
\end{tabular}

Chennai city for the same period were obtained from the Pollution Control Board (PCB) and the United States Embassy (USE) ambient air quality monitoring stations (Fig. 1).

Chennai is located on the east coast of India, along the Bay of Bengal, and experiences a tropical wet and dry climate. The metropolitan area of Chennai is approximately $426 \mathrm{~km}^{2}$, with a population of more than 10 million. It is the fourth largest megacity in India (https://population. un.org). Modeled annual mean \pm standard deviation concentrations of $\mathrm{PM}_{10}, \mathrm{PM}_{2.5}, \mathrm{SO}_{2}$, and $\mathrm{NO}_{2}$ are reported to be $199.8 \pm 101.5 \mu \mathrm{g} \mathrm{m}^{-3}, 57.5 \pm 16.8 \mu \mathrm{g} \mathrm{m}^{-3}, 65.5 \pm 37.1 \mu \mathrm{g} \mathrm{m}^{-3}$, and $39.7 \pm 31.8$ $\mu \mathrm{g} \mathrm{m}^{-3}$, respectively (Guttikunda et al., 2019). The ambient $\mathrm{PM}_{2.5}$ levels in Chennai are $1.4 \times$ and $5 \times$ higher than the national standard $\left(40 \mu \mathrm{g} \mathrm{m}^{-3}\right)$ and the WHO guideline value $\left(10 \mu \mathrm{g} \mathrm{m}^{-3}\right)$, respectively. Transport (i.e., freight movement, on-road dust), industry (including two coal-fired power plants), open waste burning (widespread and unregulated), and clusters of brick kilns ( 430 in the urban air-shed) are the dominant sources of ambient air pollution in Chennai (Guttikunda et al., 2019).

\subsection{Instrumentation}

\subsubsection{Atmos sensor}

Atmos $^{\mathrm{TM}}$ (Respirer Living Sciences Private Limited, Pune, India) is an affordable, portable, locally assembled, real-time particulate matter (PM) monitor capable of measuring $\mathrm{PM}_{1}, \mathrm{PM}_{2.5}, \mathrm{PM}_{10}$, temperature $(\mathrm{T})$, and relative humidity $(\mathrm{RH})$ simultaneously. Atmos uses a Plantower ${ }^{\mathrm{TM}} \mathrm{PMS7003}$ sensor to measure size-differentiated PM concentrations. A micro fan draws air into the measurement chamber and light scattering is used to detect particles. The output of PMS7003 is based on the intensity of the light scattered by the particles. Atmos provides output both in terms 

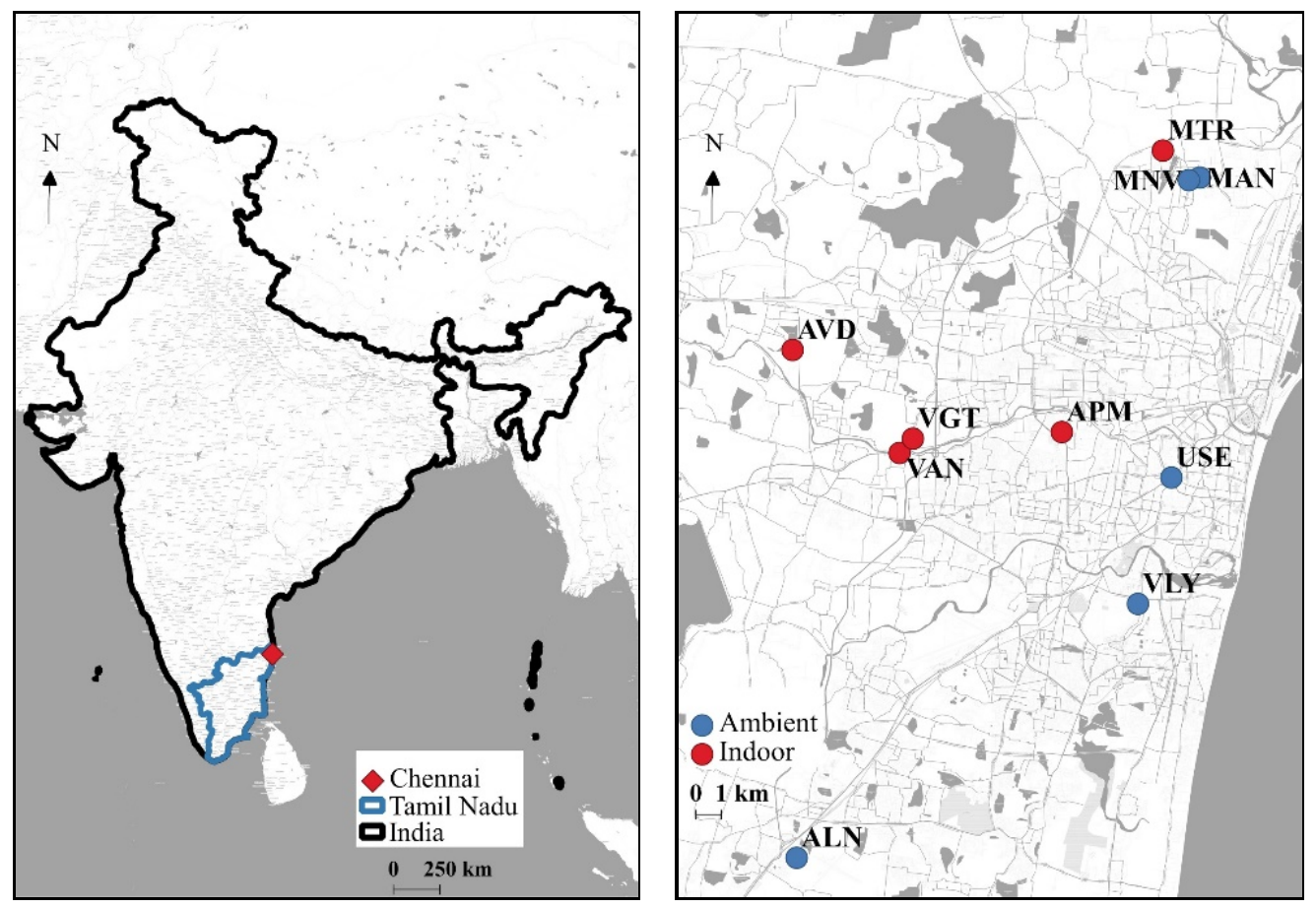

Fig. 1. Geographical locations of the indoor (red dots) and ambient (blue dots) PM monitors in urban Chennai.

of number and mass (derived using a proprietary algorithm) concentrations at various size fractions. The operating temperature and humidity ranges of PMS7003 are $-10^{\circ} \mathrm{C}$ to $+60^{\circ} \mathrm{C}$ and $0 \%$ to $99 \%$, respectively. The resolution of the atmos mass concentration data is $1 \mu \mathrm{g} \mathrm{m}^{-3}$, while the maximum error in the reported values is $\pm 10 \mu \mathrm{g} \mathrm{m}^{-3}$ (for mass concentrations less than $100 \mu \mathrm{g} \mathrm{m}^{-3}$ ) or $10 \%$ (for mass concentrations in the range $100-500 \mu \mathrm{g} \mathrm{m}^{-3}$ ). A DHT22 environmental sensor is used in atmos to measure humidity and temperature. Atmos transmits recorded data to a cloud server (in addition to storing data locally) and data can be accessed via a customized personal dashboard. More details on the assembly, packaging, data transfer protocols, and operational limitations of the atmos monitor can be found in Sahu et al. (2020). In the current study, atmos monitors were configured to log data at one-minute averaging time intervals. The monitors were installed in the living rooms of five study houses.

\subsubsection{Beta attenuation monitor}

Regulatory ambient $\mathrm{PM}_{2.5}$ measurements routinely made by Pollution Control Board authorities and the United States (US) Embassy were used in the study. A BAM1020 ${ }^{\mathrm{rM}}$ (Met One Instruments, Inc., Grants Pass, USA) is generally used in India to measure regulatory PM. BAM1020 is designated as a Federal Equivalent Method (FEM) by the U.S. Environmental Protection Agency (U.S. EPA) for near real-time (hourly) measurement of $\mathrm{PM}_{2.5}$ and $\mathrm{PM}_{10}$. BAM1020 employs beta attenuation technique (beta source: ${ }^{14} \mathrm{C}$ ) and the Beer-Lambert law to quantify PM. BAM1020 collects PM samples at 16.7 LPM (liters per minute) on glass fiber filter tape and is equipped with sharp cut size-selective cyclone. High-energy electrons (beta rays) are bombarded on the PM-laden filter tape and the transmitted beta rays are detected by a scintillation detector. The difference in beta attenuation before and after the PM sample deposition is converted into PM mass concentration using a manufacturer-supplied calibration constant. BAM1020 is equipped with an inbuilt inlet heater to avoid humidity-related biases in the measurement. The operating temperature range of BAM 1020 is $0^{\circ} \mathrm{C}$ to $+50^{\circ} \mathrm{C}$. The accuracy of the BAM 1020 data exceeds the U.S. EPA class III FEM standards. Further details on BAM1020 can be found at https://metone.com/products/bam-1020/.

\subsubsection{Collocation experiments}

Optical scattering-based PM measurements are known to be sensitive to various environmental 
and aerosol micro-physical properties. A local calibration is always preferred to correct optical PM measurements (e.g., Zheng et al., 2018). To derive the local calibration equation for atmosmeasured $\mathrm{PM}_{2.5}$ and $\mathrm{PM}_{10}$, all five atmos monitors were collocated with two BAM1020s, each measuring $\mathrm{PM}_{2.5}$ and $\mathrm{PM}_{10}$ separately. The collocation experiment lasted for a two-week period during December 2020 and January 2021 at the Center for Air Quality, Climate Change and Health in Sri Ramachandra Institute of Higher Education and Research (SRIHER), Chennai. The BAM1020s installed at the SRIHER campus are part of the Modeling Air Pollution and Networking (MAPAN) network of the Indian Institute of Tropical Meteorology (IITM), Pune. During the experiment, all the five atmos monitors were temporarily installed close to the BAM inlet (at a height of $\sim 10 \mathrm{~m}$ above ground) in the ambient atmosphere.

\subsection{Data Processing}

One-minute data from the atmos monitors were averaged to hourly time resolutions. Both the ambient and indoor data were thoroughly checked for negative values, fill-values, and missing data. The amount of ambient and indoor PM measurements used in the study is detailed in Tables S1 and S2 (supplementary information). All statistics presented in the study were computed based on hourly mean PM. Hourly ambient PM 2.5 (ambient PM $_{10}$ data was not available during the study period) was downloaded from the Central Pollution Control Board (CPCB) (https://app.cpcbccr.com/) and the AirNow (www.airnow.gov) dashboards. Data collected during the collocation experiment was used to develop the calibration equations to correct PM measured by atmos sensors. The performance of the calibration equations was evaluated using $75 \%$ as training data and $25 \%$ as validation data. Using the ambient and calibrated indoor $\mathrm{PM}_{2.5}$ measurements, indoor-to-outdoor $\mathrm{PM}_{2.5}$ ratios ( $\left.\mathrm{I} / \mathrm{O}\right)$ were estimated. For this exercise, hourly $\mathrm{PM}_{2.5}$ data from all indoor locations were averaged, and hourly ambient $\mathrm{PM}_{2.5}$ from all the locations was averaged. All analysis presented in the study was carried out using the R programming language (version 4.0.5, R Core Team (2021)).

\section{RESULTS AND DISCUSSION}

\subsection{Atmos PM Calibration}

Hourly time-series of atmos and BAM1020 measured PM (PM2.5 and $\left.\mathrm{PM}_{10}\right)$ during the collocation period are shown in Fig. 2. The collocation experiment was conducted after the main study; derived calibration coefficients were applied retrospectively to atmos measurements made during the lockdown phases. Atmos overestimated BAM1020 PM2.5 measurements, while underestimating BAM1020 PM10 measurements (Fig. 2). A similar pattern in atmos PM measurements was also reported by Sahu et al. (2020). An inter-sensor absolute bias of 0 to $67 \mu \mathrm{g} \mathrm{m}^{-3}$ (mean: $7.6 \mu \mathrm{g} \mathrm{m}^{-3}$; median: $5.64 \mu \mathrm{g} \mathrm{m}^{-3}$ ) in atmos hourly $\mathrm{PM}_{2.5}$ and 0 to $57 \mu \mathrm{g} \mathrm{m}^{-3}$ (mean: $7.1 \mu \mathrm{g} \mathrm{m}^{-3}$; median: 5.03 $\mu \mathrm{g} \mathrm{m}^{-3}$ ) in atmos hourly $\mathrm{PM}_{10}$ among the five collocated sensors was observed (Fig. 2). Due to the observed inter-sensor variability in PM measurements, sensor-specific regression models were developed (separately for $\mathrm{PM}_{2.5}$ and $\mathrm{PM}_{10}$ ) using collocation data to derive the field calibration (regression) coefficients. The form of the developed models is as shown below:

$$
\begin{aligned}
& \mathrm{PM}_{2.5(B A M)}=a \times \mathrm{PM}_{2.5(\text { atmos })}+b \times T+c+\varepsilon \\
& \mathrm{PM}_{10(B A M)}=a \times \mathrm{PM}_{10 \text { (atmos) })}+b \times T+c+\varepsilon
\end{aligned}
$$

where $a$ and $b$ are the regression coefficients, $c$ is the intercept, and $\varepsilon$ is the error term. $T$ represents the temperature measured by atmos. The regression coefficients obtained for individual monitors are listed in Tables S3 and S4. Relative humidity $(\mathrm{RH})$ data is not included in the above equations due to its unavailability during the collocation experiment.

To assess the accuracy of the model, corrected hourly atmos $\mathrm{PM}_{2.5}$ and $\mathrm{PM}_{10}$ data were regressed against BAM1020 measurements (Fig. 3). A similar plot between uncorrected (raw) atmos $\mathrm{PM}_{2.5}$ and $\mathrm{PM}_{10}$ versus BAM1020 measurements is shown in Fig. S1. The accuracy and precision of the atmos measurements have shown an improvement after the correction. The corrected atmos $\mathrm{PM}_{2.5}$ data was more accurate compared to that of corrected $\mathrm{PM}_{10}$ data (Fig. 3). 

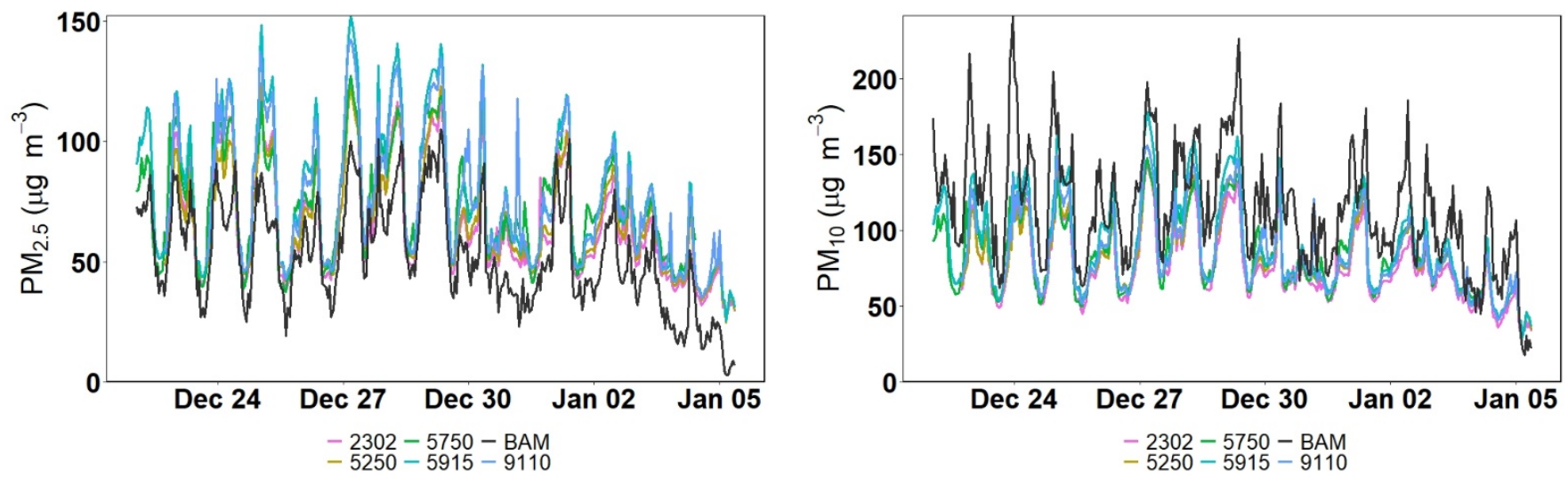

Fig. 2. Hourly time series of $\mathrm{PM}_{2.5}$ and $\mathrm{PM}_{10}$ of the five collocated atmos monitors and the BAM1020. The collocation period spanned 14 days. The black line represents the BAM1020 data. The individual atmos monitors are identified by the last four digits of their International Mobile Equipment Identity (IMEI) number.
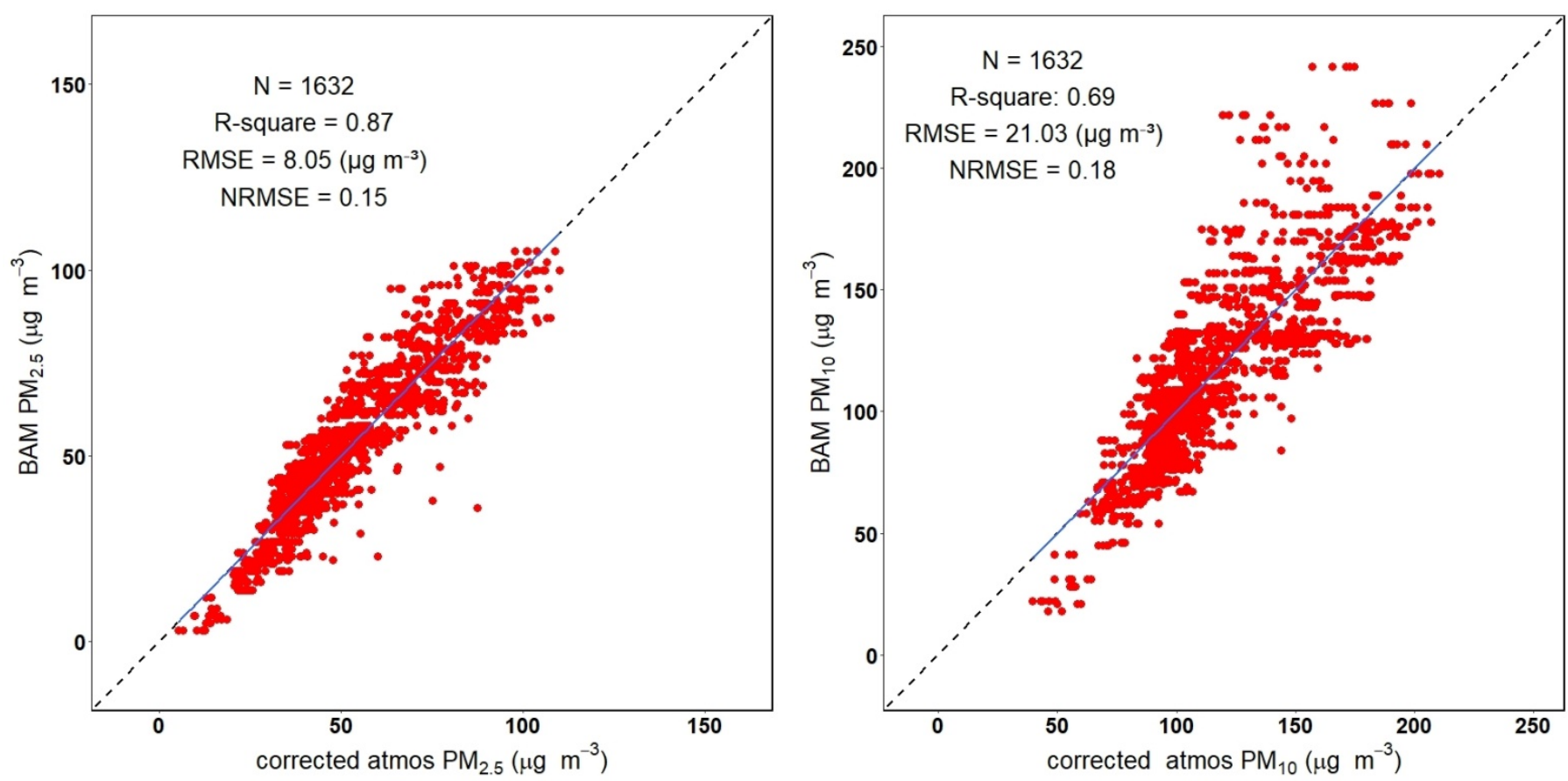

Fig. 3. Scatter plots of corrected atmos $\mathrm{PM}_{2.5}$ versus BAM1020 $\mathrm{PM}_{2.5}$ (top panel); corrected atmos $\mathrm{PM}_{10}$ versus $\mathrm{BAM} 1020 \mathrm{PM} 10$ (bottom panel).

This is evident in terms of an improved coefficient of determination $\left(R^{2}\right)$, root mean square error (RMSE), and normalized RMSE (NRMSE) for $\mathrm{PM}_{2.5}$ (Fig. 3). Further, the cross-validation analysis also showed that the accuracy in corrected $\mathrm{PM}_{2.5}\left(\mathrm{R}^{2}=0.88\right.$, RMSE $\left.=7.65 \mu \mathrm{g} \mathrm{m}^{-3}\right)$ was better compared to corrected $\mathrm{PM}_{10}\left(\mathrm{R}^{2}=0.44, \mathrm{RMSE}=34.12 \mu \mathrm{g} \mathrm{m}^{-3}\right)$ (Fig. S2). Sensor-specific calibration factors were applied to correct the indoor atmos data collected during the lockdown. Throughout the rest of the manuscript, indoor $\mathrm{PM}_{2.5}$ and $\mathrm{PM}_{10}$ represent corrected atmos data.

\subsection{Ambient $\mathrm{PM}_{2.5}$}

Fig. 4 depicts the temporal variation in hourly ambient $\mathrm{PM}_{2.5}$ during lockdown phases at various regulatory ambient pollution measurement locations in Chennai. Compared to prelockdown (PL) ambient levels, $\mathrm{PM}_{2.5}$ during lockdown phases (i.e., L1, L2, L3, and L4) were lower (Fig. 4). The highest reduction (in the range of $\sim 28-70 \%$ ) was observed in L2 and L3 (lockdown phases 2 and 3), during which all non-emergency outdoor activities were restricted (Fig. 5). The 


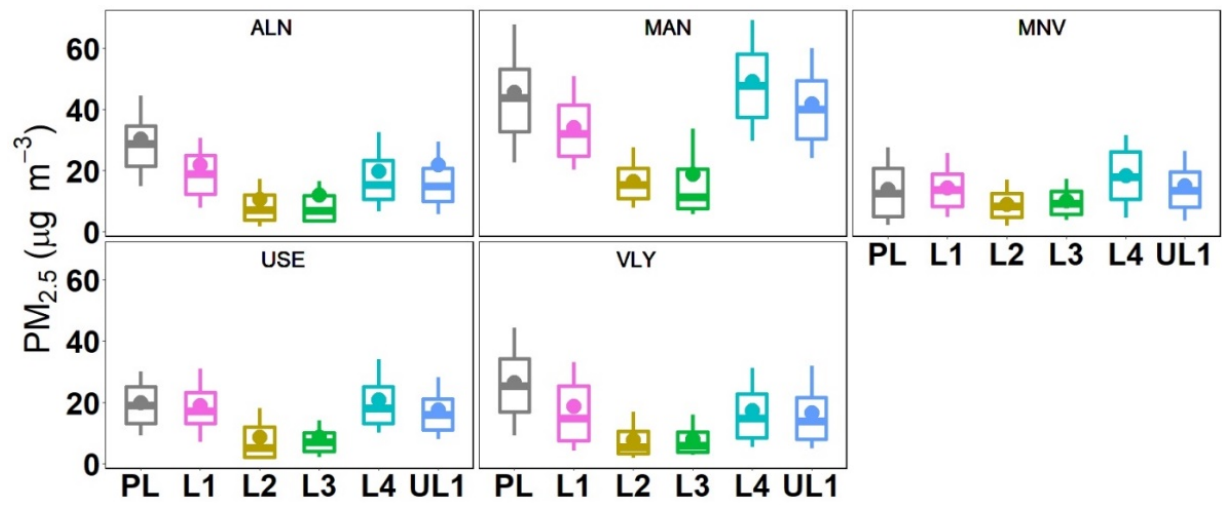

Fig. 4. Box and whisker plots depicting the temporal variations of hourly $\mathrm{PM}_{2.5}$ at various ambient PM measurement locations in Chennai during pre-lockdown and lockdown phases. The dot indicates the mean, and whiskers indicate 10 and 90 percentile values. The central horizontal line in the box indicates the median values and the range of the box indicates the inter-quartile range. ALN, MAN, MNV, USE, and VLY stand for Alandur bus depot, Manali, Manali village, United States Embassy, and Velachery residential area, respectively.

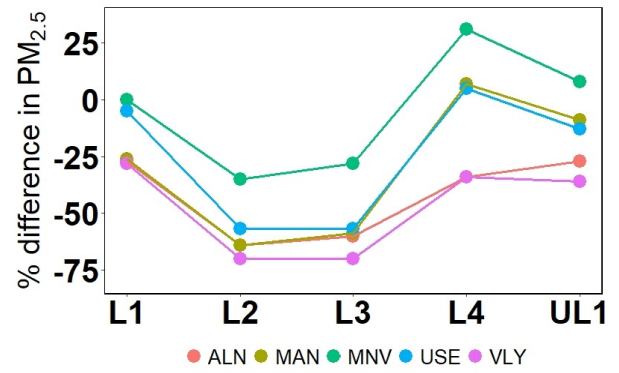

Fig. 5. Percentage difference in ambient $\mathrm{PM}_{2.5}$ during various lockdown phases with respect to the levels observed during pre-lockdown (PL). The negative sign indicates reduction. Different colors correspond to different ambient $\mathrm{PM}_{2.5}$ measurement locations.

reduction in $\mathrm{L}_{1} \mathrm{PM}_{2.5}$ ranged between $0 \%$ and $41 \%$ and the levels recovered through $\mathrm{L} 4$ which were comparable to that of PL (Fig. 5 and Table S5). Diurnal variations in $\mathrm{PM}_{2.5}$ during various lockdown phases are shown in Fig. S3. No systematic $\mathrm{PM}_{2.5}$ reduction was observed across hours of the day during different lockdown phases (Fig. S3). Further, when compared with the climatological (2015-2019) mean ambient $\mathrm{PM}_{2.5}$ for the same period, the lockdown period $\mathrm{PM}_{2.5}$ levels were significantly lower at all ambient monitoring locations (Fig. S4). As all the lockdown phases happened mostly during the same season (i.e., pre-monsoon), the observed reduction can be attributed to reduced anthropogenic activities during the lockdown. These observations are in line with that of earlier studies reporting reduction in ambient PM levels during the lockdown period. $\mathrm{M}_{10}$ data from ambient monitors were not available during the lockdown period. In a recent study, Kumar et al. (2020) reported a $10 \%$ to $43 \%$ reduction in ambient $\mathrm{PM}_{2.5}$ (compared to climatological mean) in Chennai during the initial phases of lockdown. The differences in the reported percentage reduction in the pollutant level in a particular city were mostly due to the differences in the study period considered and the choice of the control period. Kumar et al. (2020) also reported a percentage reduction in $\mathrm{PM}_{2.5}$ during lockdown for other Indian metropolitan cities of Delhi (41-53\%), Hyderabad (26-54\%), Kolkata (24-36\%), and Mumbai (10$39 \%)$. Over Bengaluru, Sreekanth et al. (2021) reported $\sim 15-22 \%$ reduction in ambient $\mathrm{PM}_{2.5}$ (across various regulatory measurement locations within the city) during the early phases of the lockdown and attributed the same to reduced vehicular activities. On the diurnal scale, Sreekanth et al. (2021) observed a consistent decrease in $\mathrm{PM}_{2.5}$ throughout the day during lockdown with respect to $\mathrm{PL}$ levels. Serval studies reported a reduction in other criteria pollutant levels $\left(\mathrm{PM}_{10}\right.$, $\mathrm{NO}_{2}, \mathrm{CO}$, etc.) during COVID-19 lockdown (e.g., Jain and Sharma, 2020). Reduced ambient pollution 
levels were reported from several locations across the globe due to COVID-19 lockdown and restricted human activities (e.g., Nakada et al., 2020; Lian et al., 2020). However, an increase in surface ozone $\left(\mathrm{O}_{3}\right)$ during lockdown was observed in cities across the world (e.g., Mahato and Ghosh, 2020; Sicard et al., 2020).

\subsection{Indoor Particulate Matter}

For the five houses sampled, data was available on an average for 8 (range: 3-13), 61, and 30 days during pre-lockdown, lockdown, and unlock phases, respectively (Table S2). Temporal variations in hourly indoor $\mathrm{PM}$ and the $\mathrm{PM}_{2.5} / \mathrm{PM}_{10}$ ratio during the pre-lockdown, lockdown, and unlock phases are shown in Fig. 6. The highest indoor PM levels (PM10: $106 \mu \mathrm{g} \mathrm{m}^{-3} ; \mathrm{PM}_{2.5}: 48$ $\mu \mathrm{g} \mathrm{m}^{-3}$ ) during PL were recorded in VAN (Fig. 6 and Tables S6 and S7). This could be due to multiple factors, but most importantly, due to its proximity to the highway, an active smoker in the house, and the large family size (Table 2). The pre-lockdown (PL) hourly indoor $\mathrm{PM}_{2.5}$ and $\mathrm{PM}_{10}$ levels in other homes ranged from 24 to $32 \mu \mathrm{g} \mathrm{m}^{-3}$ and 62 to $78 \mu \mathrm{g} \mathrm{m}^{-3}$, respectively (Tables S6 and S7). Across the different phases of lockdown (i.e., L1 through L4), the hourly indoor PM 2.5 and $\mathrm{PM}_{10}$ concentrations ranged from 3 to $47 \mu \mathrm{g} \mathrm{m}^{-3}$ and 26 to $100 \mu \mathrm{g} \mathrm{m}^{-3}$, respectively (Fig. 6, Tables S6 and S7). The highest reduction in indoor PM levels was observed during L2 and L3 phases (Fig. 7 and S6). A similar pattern in reduction was also observed in ambient PM2.5 (Fig. 5).

The percent reduction in indoor PM levels (relative to PL) across all lockdown phases was highest in AVD and lowest in APM (Fig. 7). Only VGT showed a contrasting trend compared to other homes, wherein the indoor $\mathrm{PM}_{2.5}\left(\mathrm{PM}_{10}\right)$ levels were reduced to $50 \%(41 \%)$ of $\mathrm{PL}$ levels during $L 2$ and $L 3$, and started to increase during L4 and UL1 (Fig. 7). We learnt that the residents
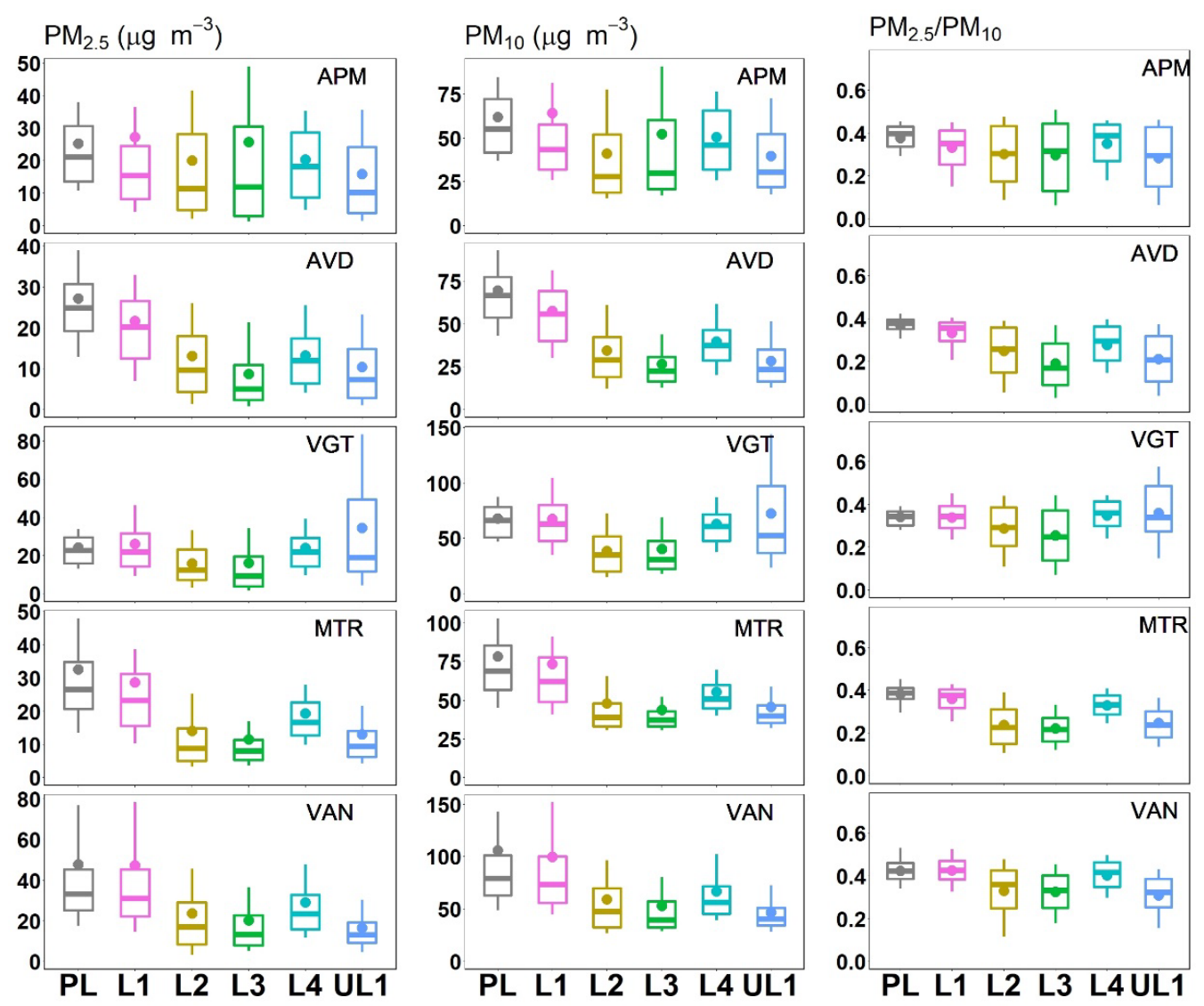

Fig. 6. Box and whisker plots depicting the variations in hourly indoor $\mathrm{PM}_{2.5}, \mathrm{PM}_{10}$, and $\mathrm{PM}_{2.5} / \mathrm{PM}_{10}$ ratio during pre-lockdown and lockdown phases. APM, AVD, VGT, MTR, and VAN stand for Arumbakkam, Avadi, Vanagaram-GT, Mathur, and Vanagaram, respectively. Note: VGT sensor was placed in near outdoor location during L4 and UL1 phases since the residents were away during this period. 

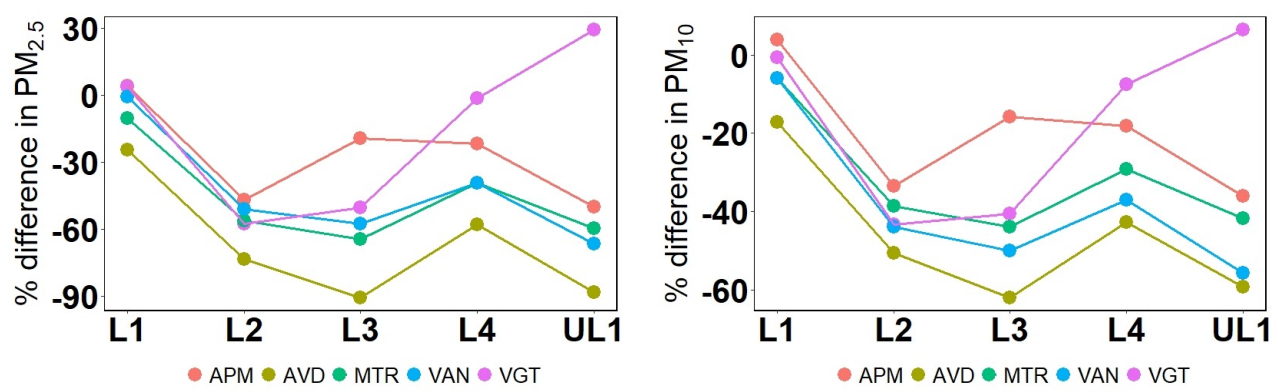

Fig. 7. Percentage difference in indoor $\mathrm{PM}_{2.5}$ and $\mathrm{PM}_{10}$ during various lockdown phases with respect to the levels observed during pre-lockdown $(\mathrm{PL})$. The negative sign indicates reduction. Note: VGT sensor was placed in near outdoor location during L4 and UL1 phases since the residents were away during this period.

of VGT left the sensor in a near outdoor location (placed in the balcony) as they moved out during L4 and UL1 periods. The mean \pm SD PM 2.5 in VGT during L4 was $24 \pm 19 \mu \mathrm{g} \mathrm{m}^{-3}$, which was comparable to that of ambient levels $21 \pm 13 \mu \mathrm{g} \mathrm{m}^{-3}$, as recorded by the nearest ambient monitoring station (USE) (Tables S5 and S6). The highest reduction in $\mathrm{PM}_{2.5}\left(\mathrm{PM}_{10}\right)$ of $\sim 91$ (62) \% was observed in AVD home during L3 phase (Figs. 6 and 7). The residents of AVD could not be contacted during L3 through UL1 phase. It is possible that the sensor was left indoor and the residents were away from home during these phases.

Diurnal variations in indoor $\mathrm{PM}_{2.5}$ and $\mathrm{PM}_{10}$ during pre-lockdown and lockdown phases are shown in Fig. S5 (supplemental information). No consistent pattern in diurnal PM levels was observed across the study houses (Fig. S5). Diurnal variations were characterized by multiple peaks, which could be due to specific indoor activities. Also, note that the classical bi-modal diurnal pattern in ambient $\mathrm{PM}_{2.5}$ was also not observed in ALN (Fig. S3).

Leveraging on the simultaneous $\mathrm{PM}_{2.5}$ and $\mathrm{PM}_{10}$ measurements by atmos monitors, the indoor $\mathrm{PM}_{2.5} / \mathrm{PM}_{10}$ ratios were computed. This ratio signifies the relative dominance of fine/coarse particle mass concentration in $\mathrm{PM}_{10}$. The ratio ranged between 0.37 and 0.42 during $\mathrm{PL}$ (Fig. 6). A marginal decrease in the indoor $\mathrm{PM}_{2.5} / \mathrm{PM}_{10}$ ratio was observed during L2 and L3 in APM, VAN, and VGT, while the decrement was higher in MTR and AVD. This implies that the relative dominance of fine particulate matter (mostly of anthropogenic origin) decreased during L2 and L3 phases. $\mathrm{L} 4$ indoor $\mathrm{PM}_{2.5} / \mathrm{PM}_{10}$ ratios were comparable to that of $\mathrm{PL}$, while UL1 ratios were lower compared to that of $\mathrm{L} 4$ (Fig. 6). A similar decreasing trend in the $\mathrm{PM}_{2.5} / \mathrm{PM}_{10}$ ratio (by $\sim 25 \%$ ) during the lockdown was also observed in the cities of Seoul and Daegu (Korea) and was attributed to a decrease in anthropogenic emissions (Seo et al., 2020).

Based on the average hourly ambient and indoor data, indoor-to-outdoor (I/O) ratios in $\mathrm{PM}_{2.5}$ were estimated across different lockdown phases. During PL, the mean I/O ratio was very close to unity (Fig. 8). An I/O ratio of less than unity is always preferred, implying that the homes offer a method of reduction to outside PM exposure (Nadali et al., 2020). During L1, L2, and L3, the mean I/O values were close to or above one (Fig. 8 and Table S8). This could be due to the uneven decrease in ambient and indoor $\mathrm{PM}_{2.5}$ levels. Also, during the lockdown, the distribution of $\mathrm{I} / \mathrm{O}$ values was comparatively broad (with higher standard deviation and interquartile range) implying

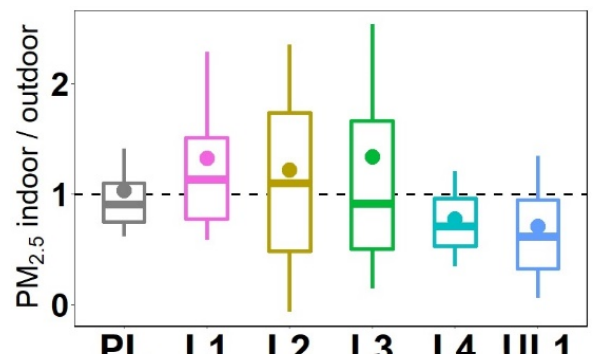

Fig. 8. Indoor-to-outdoor ratios in hourly $\mathrm{PM}_{2.5}$ during pre-lockdown and lockdown phases. 
variability in indoor activities and sources (Table S8). During L4 and UL1, the I/O ratios were less than one unity (Fig. 8). With relaxations in movement in L4 and UL1 phases, the ambient PM levels gradually returned to PL levels resulting in an I/O ratio close to 1 . While the indoor and ambient $\mathrm{PM}_{2.5}$ levels decreased during the lockdown phases, there was a marginal increase in $\mathrm{I} / \mathrm{O}$ ratio (i.e., $1 / O>1$ ) indicating high indoor $\mathrm{PM}_{2.5}$ levels compared to ambient levels. As people spent more time indoors, cooking activities could have contributed significantly to indoor PM levels along with other indoor sources such as incense burning, mosquito repellants etc., that are typical to Indian households.

\subsection{Limitations}

The response (i.e., accuracy) of low-cost or affordable PM sensors is of paramount importance in air pollution research and health effect studies. Response of the Plantower sensor (i.e., PMS used in atmos) has been shown to vary with particle properties. For instance, the PMS response to coarse particles either remains unchanged or biased compared to reference monitor (Kelly et al., 2017; Tryner et al., 2020). In the present study, PM10 accuracy was poor (i.e., high RMSE value) compared to $\mathrm{PM}_{2.5}$. Therefore, the results of $\mathrm{PM}_{10}$ presented here should be interpreted with caution. Field calibration of atmos monitors was conducted in the ambient atmosphere, and the calibration coefficients were applied on indoor monitored PM data. This can lead to bias in the corrected data if the optical characteristics of indoor PM differ significantly from that of outdoors. Yet, due to the high ventilation characteristics of the houses in this study, this effect could be termed minimal. Another limitation was the unavailability of $\mathrm{RH}$ data for developing calibration equations for atmos PM correction. Also, the current study was limited to five houses in urban Chennai with 3 to 13 days of pre-lockdown measurements. However, these households are representative of low and middle socio-economic groups of urban Chennai. We took advantage of the forced lockdown to assess temporal variation in indoor PM levels. Therefore, this was an opportunistic study rather than a planned execution.

\section{CONCLUSIONS}

The study evaluated the impact of graded COVID-19 lockdown on the indoor and ambient PM levels in Chennai, a megacity in South India. Indoor PM ( $\mathrm{PM}_{2.5}$ and $\left.\mathrm{PM}_{10}\right)$ levels in typical urban households were based on the calibrated data from affordable real-time atmos sensors and ambient PM levels were obtained from publicly available regulatory monitors. Over 100 days of continuous PM data were captured that coincided with pre-lockdown, lockdown, and unlock phases between March and June 2020. Plantower ${ }^{\mathrm{TM}}$-based atmos PM monitors overestimated reference $\mathrm{PM}_{2.5}$ and underestimated reference $P M_{10}$. Multiple linear regression-based calibration models (with temperature as auxiliary predictor) performed superior in correcting the sensor-based $\mathrm{PM}_{2.5}$ compared to that of $\mathrm{PM}_{10}$. Pre-lockdown levels of indoor $\mathrm{PM}_{2.5}\left(\mathrm{PM}_{10}\right)$ ranged between $24 \mu \mathrm{g} \mathrm{m}^{-3}$ and $48 \mu \mathrm{g} \mathrm{m}^{-3}\left(64 \mu \mathrm{g} \mathrm{m}^{-3}\right.$ and $106 \mu \mathrm{g} \mathrm{m}^{-3}$ ). The highest reduction (with respect to prelockdown levels) in indoor and ambient $\mathrm{PM}_{2.5}$ was observed during the second and third phases of lockdown (15 April 2020-17 May 2020). Indoor $\mathrm{PM}_{2.5} / \mathrm{PM}_{10}$ ratios marginally decreased during the lockdown. Mean indoor-to-outdoor (I/O) ratios in $\mathrm{PM}_{2.5}$ marginally increased during the lockdown, implying an uneven reduction in ambient and indoor $\mathrm{PM}_{2.5}$

\section{ADDITIONAL INFORMATION}

\section{Ethics Approval}

The study protocol has been reviewed and approved by the Institutional Ethics Committee (IEC) at Sri Ramachandra Institute of Higher Education and Research (IEC-NI/19/FEB/68/19).

\section{Consent to Participate}

All participants included in the study provided informed consent to install the real-time monitors in their homes. 


\section{ACKNOWLEDGEMENTS}

The Tamil Nadu Air Pollution and Health Effects (TAPHE-2) cohort study was funded by the Indian Council of Medical Research (ICMR), Department of Health Research, Ministry of Health and Family Welfare, Government of India and awarded to Sri Ramachandra Institute of Higher Education and Research, Chennai, India under the grant number: 5/7/1655/CH/Adhoc/2019RBMCH.

\section{SUPPLEMENTARY MATERIAL}

Supplementary material for this article can be found in the online version at https://doi. org/10.4209/aaqr.210170

\section{REFERENCES}

Balakrishnan, K., Dey, S., Gupta, T., Dhaliwal, R.S., Brauer, M., Cohen, A.J., Stanaway, J.D., Beig, G., Joshi, T.K., Aggarwal, A.N., Sabde, Y. (2019). The impact of air pollution on deaths, disease burden, and life expectancy across the states of India: The Global Burden of Disease Study 2017. Lancet Planet. Health. 3, e26-e39. https://doi.org/10.1016/S2542-5196(18)30261-4

Brauer, M., Guttikunda, S.K., Nishad, K.A., Dey, S., Tripathi, S.N., Weagle, C., Martin, R.V. (2019). Examination of monitoring approaches for ambient air pollution: A case study for India. Atmos. Environ. 216, 116940. https://doi.org/10.1016/j.atmosenv/2019.116940

Guttikunda, S.K., Nishadh, K.A., Jawahar, P. (2019). Air pollution knowledge assessments (APnA) for 20 Indian cities. Urban Clim. 27, 124-141. https://doi.org/10.1016/j.uclim.2018.11.005

Health Effects Institute (HEI) (2020). State of Global Air 2020. Special Report. Health Effects Institute, Boston, MA.

Jain, S., Sharma, T. (2020). Social and travel lockdown impact considering coronavirus disease (COVID-19) on air quality in megacities of India: Present benefits, future challenges and way forward. Aerosol Air Qual. Res. 20, 1222-1236. https://doi.org/10.4209/aaqr.2020.04.0171

Kelly, K.E., Whitaker, J., Petty, A., Widmer, C., Dybwad, A., Sleeth, D., Martin, R., Butterfield, A. (2017). Ambient and laboratory evaluation of a low-cost particulate matter sensor. Environ Pollut. 221, 491-500. https://doi.org/10.1016/j.envpol.2016.12.039

Kumar, P., Hama, S., Omidvarborna, H., Sharma, A., Sahani, J., Abhijith, K.V., Debele, S.E., ZavalaReyes, J.C., Barwise, Y., Tiwari, A. (2020). Temporary reduction in fine particulate matter due to 'anthropogenic emissions switch-off'during COVID-19 lockdown in Indian cities. Sustainable Cities Soc. 62, 102382. https://doi.org/10.1016/j.scs.2020.102382

Lian, X., Huang, J., Huang, R., Liu, C., Wang, L., Zhang, T. (2020). Impact of city lockdown on the air quality of COVID-19-hit of Wuhan city. Sci. Total Environ. 742, 140556. https://doi.org/10.1 016/j.scitotenv.2020.140556

Magi, B.I., Cupini, C., Francis, J., Green, M., Hauser, C. (2020). Evaluation of PM2.5 measured in an urban setting using a low-cost optical particle counter and a Federal Equivalent Method Beta Attenuation Monitor. Aerosol Sci. Technol. 54, 147-159. https://doi.org/10.1080/02786826.2 019.1619915

Mahato, S., Ghosh, K.G. (2020). Short-term exposure to ambient air quality of the most polluted Indian cities due to lockdown amid SARS-CoV-2. Environ. Res. 188, 109835. https://doi.org/10. 1016/j.envres.2020.109835

Mahato, S., Pal, S., Ghosh, K.G. (2020). Effect of lockdown amid COVID-19 pandemic on air quality of the megacity Delhi, India. Sci. Total Environ. 730, 139086. https://doi.org/10.1016/j.scitote nv.2020.139086

Malings, C., Tanzer, R., Hauryliuk, A., Saha, P.K., Robinson, A.L., Presto, A.A., Subramanian, R. (2020). Fine particle mass monitoring with low-cost sensors: Corrections and long-term performance evaluation. Aerosol Sci. Technol. 54, 160-174. https://doi.org/10.1080/0278682 6.2019.1623863

Mor, S., Kumar, S., Singh, T., Dogra, S., Pandey, V., Ravindra, K. (2021). Impact of COVID-19 
lockdown on air quality in Chandigarh, India: understanding the emission sources during controlled anthropogenic activities. Chemosphere 263, 127978. https://doi.org/10.1016/j.che mosphere.2020.127978

Nadali, A., Arfaeinia, H., Asadgol, Z., Fahiminia, M. (2020). Indoor and outdoor concentration of $\mathrm{PM}_{10}, \mathrm{PM}_{2.5}$ and $\mathrm{PM}_{1}$ in residential building and evaluation of negative air ions (NAIs) in indoor PM removal. Environ. Pollut. Bioavailability 32, 47-55. https://doi.org/10.1080/26395940.202 0.1728198

Nakada, L.Y.K., Urban, R.C. (2020). COVID-19 pandemic: Impacts on the air quality during the partial lockdown in São Paulo state, Brazil. Sci. Total Environ. 730, 139087. https://doi.org/10. 1016/j.scitotenv.2020.139087

Panda, S., Mallik, C., Nath, J., Das, T., Ramasamy, B. (2021). A study on variation of Atmospheric pollutants over Bhubaneswar during imposition of nationwide lockdown in India for the COVID-19 pandemic. Air Qual. Atmos. Health 14, 97-108. https://doi.org/10.1007/s11869020-00916-5

R Core Team (2021). R: A language and environment for statistical computing. R Foundation for Statistical Computing, Vienna, Austria. https://www.R-project.org/

Sahu, R., Dixit, K.K., Mishra, S., Kumar, P., Shukla, A.K., Sutaria, R., Tiwari, S., Tripathi, S.N. (2020). Validation of low-cost sensors in measuring real-time $\mathrm{PM}_{10}$ concentrations at two sites in Delhi national capital region. Sensors 20, 1347. https://doi.org/10.3390/s20051347

Sanchez, M., Milà, C., Sreekanth, V., Balakrishnan, K., Sambandam, S., Nieuwenhuijsen, M., Kinra, S., Marshall, J.D., Tonne, C. (2020). Personal exposure to particulate matter in peri-urban India: predictors and association with ambient concentration at residence. J. Exposure Sci. Environ. Epidemiol. 30, 596-605. https://doi.org/10.1038/s41370-019-0150-5

Seo, J.H., Kim, J.S., Yang, J., Yun, H., Roh, M., Kim, J.W., Yu, S., Jeong, N.N., Jeon, H.W., Choi, J.S. Sohn, J.R. (2020). Changes in air quality during the covid-19 pandemic and associated health benefits in Korea. Appl. Sci. 10, 8720. https://doi.org/10.3390/app10238720

Sicard, P., De Marco, A., Agathokleous, E., Feng, Z., Xu, X., Paoletti, E., Rodriguez, J.J.D., Calatayud, V. (2020). Amplified ozone pollution in cities during the COVID-19 lockdown. Sci. Total Environ. 735, 139542. https://doi.org/10.1016/j.scitotenv.2020.139542

Singh, J., Tyagi, B. (2021). Transformation of air quality over a coastal tropical station Chennai during COVID-19 lockdown in India. Aerosol Air Qual. Res. 21, 200490. https://doi.org/10.420 9/aaqr.200490

Sreekanth, V., Kushwaha, M., Kulkarni, P., Upadhya, A.R., Spandana, B., Prabhu, V. (2021). Impact of COVID-19 lockdown on the fine particulate matter concentration levels: Results from Bengaluru megacity, India. Adv. Space Res. 67, 2140-2150. https://doi.org/10.1016/j.asr.2021. 01.017

Tryner, J., Mehaffy, J., Miller-Lionberg, D., Volckens, J. (2020). Effects of aerosol type and simulated aging on performance of low-cost PM sensors. J Aerosol Sci. 150, 105654. https://doi.org/10.1016/j.jaerosci.2020.105654

Zheng, T., Bergin, M.H., Johnson, K.K., Tripathi, S.N., Shirodkar, S., Landis, M.S., Sutaria, R., Carlson, D.E. (2018). Field evaluation of low-cost particulate matter sensors in high-and lowconcentration environments. Atmos. Meas. Tech. 11, 4823-4846. https://doi.org/10.5194/amt$11-4823-2018$ 